\title{
Relationship between Job Satisfaction, Professional Image and Nurses Marketing of the Nursing Profession
}

\author{
HANY S. HUSSIEN, M.Sc. and NEHAD E. FEKRY, D.N.Sc. \\ The Department Nursing Administration, Faculty of Nursing, Cairo University
}

\begin{abstract}
Background: A global shortage of healthcare professionals calls for effective recruitment and retention strategies. One approach that has received increasing interest is the use of internal marketing to reduce occupational and organizational turnover among practicing nurses. The model links nurses' job satisfaction and organizational commitment to internal marketing programs based on principles of relationship marketing to build work environments that are more likely to lead to the engagement and retention of nursing staff. As is the case with the internal marketing of nursing, external marketing of nursing integrates marketing theory with related concepts from other areas in business. In the case of internal marketing, these concepts come from organizational psychology and include employee turnover, job satisfaction, and professional image.
\end{abstract}

Aim: The current study assess the relationship between job satisfaction, professional image and marketing of the nursing profession.

Subjects and Methods: A descriptive correlational design was utilized for this study to achieve the stated aim. The study was conducted at New Kaser El-Aini Teaching Hospital. A samples of 293 nurses were invited to participate in the questionnaire. For the purpose of this study, questionnaire for nurses was developed and utilized that consist of four parts: The first part was related to the nurse personal characteristics, the second part assess the nurses job satisfaction, the third part was related to nurses perception of professional image, the fourth part was about nurses participation in marketing activities.

Results: The study showed that the study sample has low job satisfaction with mean percentage of about $59 \%$. This may be due to work overload and inadequate salary. The study sample have moderate professional image with mean percentage of $68 \%$. This may be due to experience and about half of the sample holding academic degrees that make their professional image quite good. The study sample have very low promotional activities with mean percentage of about $36 \%$.

Conclusion: The present study concluded that there was a relationship between study sample job satisfaction \& professional image and promotional \& marketing activities. As

Correspondence to: Dr. Hany S. Hussien, The Department Nursing Administration, Faculty of Nursing, Cairo University highly satisfied nurses with high professional image perception having high level of promotional and marking activities.

Recommendations: Measure nurses job satisfaction in a regular base in order to find out areas of satisfaction to promote and areas of dissatisfaction to solve and improve. Also the study recommended developing strategies to improve nurses image throughout the nursing curriculum and implementing nursing profession marketing plan.

Key Words: Job satisfaction - Professional image-Marketing nursing profession.

\section{Introduction}

A GLOBAL shortage of healthcare professionals calls for effective recruitment and retention strategies. The nursing profession faces greater staffing shortages compared with other healthcare professions. Identifying these factors for choosing a career in health care is an important step in structuring future nursing recruitment strategies [1]. The health sector labor market in Egypt suffers from a severe shortage of qualified nurses which is a result of increased demand more than supply of nurses. The overall perceived real shortage of alltypes of nurses does not seem to be related to a shortage of the stock of all nurses but rather nurse supply decisions at the current nurse wage levels and nurse working conditions in Egypt [2]. The shortage has implications both on the quality of health care and the efficiency of the production of health care services [3]

Job satisfaction is determined by a comparison of one's prior expectations about the job and the actual experience of the job. It has been found that job satisfaction relates to beliefs and emotions that individuals have about their work and their job. It has been described as an attitude with an affective and cognitive component. When establishing the level of job satisfaction, we should focus on how 
employees feel about their work and personal relationships in the workplace, and on how leaders influence employees' satisfaction. Without a doubt, satisfied employees are the ultimate goal of every leader. On the other hand, the goal of every employee is to find the kind of work that matches their abilities and interests as closely as possible, enables them success, and provides them with opportunities for promotion. Satisfied employees tend to be more productive and committed to their employers [4].

The American Nurses Credentialing Center (ANCC) [5] reported that one of the issues that arises in the context of the recruitment and retention is the motivation of nurses to promote their profession and focus on the importance of the image of nursing as nurses are integral members of the healthcare team and should be characterized as essential by all other members of the team.

In the past, nursing suffered from a lack of knowledge and research data on the profession as a competitive career, while a poor public image in the social media added to its negative impact [6] At present there is a growing awareness that marketing of the nursing profession requires deeply needed rethinking [7]

Nursing image is conveyed by how nurses present themselves in every setting, from the classroom, to clinics, to professional meetings and to the workplace (National Students' Nurses Association). Nurses have become healthcare professionals in their own right who possess a great deal of knowledge. The public does not always value the skills and competences nurses have acquired through education and innovation [8]. The modern public image of nursing appears to be more positive but is still based on myths, misconceptions and stereotypes [9]

A negative image of the nursing profession was identified as one of the factors contributing to the present major shortage of nurses around the world due to its negative impact on the ability to recruit and retain nurses in health care [10]. However, little is known about the impact of professional on the behavior of marketing the nursing profession. so this study was conducted to examines the relationship between job satisfaction and professional self image and marketing of the nursing profession by nurses working in a selected clinical care units.

One approach that has received increasing interest is the use of internal marketing to reduce occupational and organizational turnover among practicing nurses [11]. As is the case with the internal marketing of nursing, external marketing of nursing integrates marketing theory with related concepts from other areas in business. In the case of internal marketing, these concepts come from organizational psychology and include employee turnover, job satisfaction, and professional image. With respect to the marketing of nursing as a profession, concepts are drawn from theories of occupational socialization, vocational choice, and decision-making. To effectively accomplish this objective requires insight into how prospective nurses become aware of nursing and an understanding the underlying motivations to pursue a career as a nurse. This information is critical in targeting, positioning and branding nursing, and in enhancing its image which may be a factor in improving the nursing shortage [12].

\section{Significance of the study:}

Shortage of nurses is a global problem. This problem magnified in Egypt as some newly hospitals cannot start because of the in availability of the nurses. although the number of enrolled nurses in deferent educational nursing institutions is increasing, big numbers of nurses change or leave their jobs. Review of the literature emphasized that the nursing profession has a poor image also a considerable number of nurses have either moderate or low levels of job satisfaction. satisfied nurses tend to promote and recommend their jobs positively through professional meetings, conferences, public talks and being representative for the nursing profession.

\section{Research questions:}

- What is the relationship between nurses 'job satisfaction and marketing nursing profession?

- What is the relationship between nurses' professional image and marketing of nursing profession?

- What is the relationship between nurses'Job satisfaction, professional image and nurses marketing of nursing profession?

\section{Patients and Methods}

\section{Research design:}

Descriptive correlational design was utilized to achieve the aim of this study.

\section{Setting:}

The current study was carried out at New ElKasr El-Aini Teaching Hospital from August 2016 - Feb. 2017. 


\section{Subjects:}

The number of the study sample was 293 nurses.

\section{Tools of data collection:}

It is composed of four parts as follows:

\section{Demographic data:}

Age, sex, level of education, current position, years of experience\& unit or department of work.

\section{Second part:}

Nurses' Job Satisfaction questionnaire developed after extensive review of related literature to measure nurses job satisfaction. Alikert scale of 5 points to measure respondents' opinions regarding salary and fringe benefits (5 Items), group cohesion (2 Items), work stressors (3 Items) Independence \& flexibility (3 Items), Relationship with doctors \& supervisors (4 Items), Professional pride (7 Items).

\section{Third part:}

Professional self image questionnaire developed after extensive review of related literature to measure nurses professional self- image. consisted of three parts: ${ }^{1 \mathrm{st}}$ part is alikert scale of 5 points to measure respondents' perception of their competency level at: Technical skills (5 Items), Intellectual-cognitive skills (4 Items) organizational skills (4 Items), social and communication skills (7 Items) \& professional attitude (5 Items). The second part is a likert scale of 5 points to measure Perceived importance of nursing care aspects to professional nursing (10 Items). The third part to measure respondents' perceptions of society's image of nursing (11 Items) vs. their own image of nursing (the same 11 Items) scale of (yes $=1$ and no=0) have been used

\section{Fourth part:}

Nursing promotional and marketing activity questionnaire developed after extensive review of related literature (17 Items). Alikert scale of 5 points to measure respondents' participation in promoting and marketing nursing profession .

\section{Methods of data collection:}

- Consent to conduct the study was taking from the vice dean of graduate studies at Faculty of Nursing, Cairo University and Hospital administrator.

- The tools were reviewed by jury consisted of three professors in nursing administration to be tested for its content validity.
- The investigator contacted to the nurses to explain the purpose and procedure of the study and determine the available time to collect data.

- The questionnaires were distributed to the studied sample during morning, afternoon and night shifts.

- Data collection was completed over a seven months period from August 2016 to February 2017.

\section{Ethical considerations:}

Before commencing the study, ethical approval was granted from the research ethics committee in which the study took place. The researchers ensured that the correct procedures were undertaken concerning informed consent, autonomy, anonymity and the maintenance of confidentiality.

\section{Statistical analysis:}

The collected data will be categorized, scored, tabulated, and analyzed by computer using statistical package for social science (SPSS). Descriptive statistics will be used in the form of frequency distribution and percentages. Appropriate statistical test were applied for data analysis.

\section{Results}

Table (1) shows that $(79.5 \%)$ of the study sample were females, while (40.6\%) of them were in the age group ranged from 30 to less than 40 years old. About (84.6\%) of the study sample worked as staff nurses. The educational preparation of the study sample were as follow: (49.8\%) have nursing diploma, $(32.4 \%)$ have technical institute preparation, $(16.7 \%)$ have bachelor degree of nursing and only $(1 \%)$ have master degree. (63.1\%) of the study sample had experience more than 15 years after graduation. The working units of the study sample were $(32.4 \%)$ working in ICUs, $(29.7 \%)$ in medical units, $(29.4 \%)$ in surgical units and only $(8.5 \%)$ in outpatient clinics.

Table (2) shows that $(70.01 \%)$ of the study sample agreed with the presence of work pressure followed by $(62.12 \%)$ agreed with the presence of group cohesion and only (48.31\%) of them agreed with the presence of satisfactory salary and fringe benefits.

Table (3) shows that the highest mean percentage for the study sample professional image was about (84\%) for perceived importance of nursing care aspects to professional nursing followed by 
about $(76 \%)$ for both professional attitude and social \& communication skills, while the lowest mean percentage was about (31\%) for both society's image of nursing and nurses' own image.

Table (4) shows that the study sample has low job satisfaction with mean percentage of about (59\%), while having moderate professional image with mean percentage of $(68 \%)$ and having very low promotional and marketing activities participation.

Table (5) shows that there is no relationship between study sample job satisfaction and promotional \& marketing activities ( $r=-0.036, p=0.540)$.

Table (6) shows that there is a moderate positive relationship between study sample professional image and promotional \& marketing activities ( $r=$ $0.301, p=0.000$ ).

Table (7) shows that there is a weak positive relationship between study sample total job satisfaction \& professional image and promotional \& marketing activities $(r=0.218, p=0.000)$.
Table (1): Distribution of the study sample according to personal characteristics data $(\mathrm{N}=293)$.

\begin{tabular}{lll}
\hline Item & No & $\%$ \\
\hline Sex: & & \\
Male & 60 & 20.5 \\
Female & 233 & 79.5 \\
Age: & & \\
20<30 years & 86 & 29.4 \\
30<40 years & 119 & 40.6 \\
40<50 years & 63 & 21.5 \\
50<60 years & 25 & 8.5 \\
Position: & & \\
Bed side nurse & 248 & 84.6 \\
Head nurse & 33 & 11.3 \\
Supervisor & 11 & 3.8 \\
Matron & 1 & 0.3 \\
Years of experience: & & \\
less than 5 years & 8 & 2.7 \\
5<10 years & 37 & 12.6 \\
10<15 years & 63 & 21.5 \\
>15years & 185 & 63.1 \\
Educational preparation: & & \\
Nursing diploma & 146 & 49.8 \\
Technical institute & 95 & 32.4 \\
Bachelor of nursing & 49 & 16.7 \\
Master degree & 3 & 1 \\
Department / Unit: & & \\
Medical & 87 & 29.7 \\
Surgical & 86 & 29.4 \\
ICU & 95 & 32.4 \\
Outpatient clinics & 25 & 8.5 \\
\hline
\end{tabular}

Table (2): Mean and standard deviation of respondent's perception about the level of job satisfaction (N=293).

\begin{tabular}{lccccc}
\hline Job satisfaction & Minimum & Maximum & Mean & SD & Mean \% \\
\hline Salary and fringe benefits & 5 & 22 & 12.0785 & 2.8352 & 48.31 \\
Group cohesion & 2 & 10 & 6.2116 & 1.3278 & 62.12 \\
Work pressure & 3 & 15 & 10.5017 & 2.2446 & 70.01 \\
Independence and flexibility & 3 & 15 & 8.4642 & 2.8022 & 56.43 \\
Relationship with doctors and supervisors & 4 & 18 & 12.1399 & 2.8388 & 60.70 \\
Professional Pride & 7 & 35 & 20.9420 & 4.8469 & 59.83 \\
\hline
\end{tabular}

Table (3): Mean and standard deviation of respondent`s perception about professional image ( $\mathrm{N}=293)$.

\begin{tabular}{lccccc}
\hline Professional image & Minimum & Maximum & Mean & SD & Mean \% \\
\hline Technical skills & 5 & 25 & 18.43 & 3.62 & 73.72 \\
Intellectual-cognitive Skills & 4 & 2 & 14.57 & 3.22 & 72.85 \\
Organizational skills & 4 & 20 & 14.86 & 2.68 & 74.30 \\
Social and communication skills & 13 & 35 & 26.47 & 4.53 & 75.63 \\
Professional attitude & 8 & 25 & 18.91 & 3.49 & 75.64 \\
Perceived importance of nursing care aspects & 20 & 50 & 42.13 & 6.24 & 84.26 \\
$\quad$ to professional nursing & 3 & 11 & 6.88 & 2.03 & 61.27 \\
Perceptions of society's image of nursing & 4 & 11 & 6.84 & 1.29 & 61.09 \\
Nurses' own image & & & & \\
\hline
\end{tabular}

Table (4): Mean and standard deviation of respondent's total perception ( $N=293)$.

\begin{tabular}{lccccc}
\hline Tool dimensions & Minimum & Maximum & Mean & SD & Mean \% \\
\hline Job satisfaction & 30 & 101 & 70.33 & 11.36 & 58.61 \\
Professional image & 86 & 189 & 149.09 & 18.63 & 68.08 \\
Nursing promotional and marketing activity & 17 & 85 & 30.95 & 13.98 & 36.41 \\
\hline
\end{tabular}


Table (5): Correlation between the study sample job satisfaction and promotional/ marking activities.

\begin{tabular}{lccc}
\hline Variables & $\mathrm{M} \pm \mathrm{SD}$ & $r$ & $p$ \\
\hline Nurses job satisfaction & $70.34 \pm 11.36$ & -0.036 & 0.540 \\
Nurses promotional & $30.95 \pm 13.98$ & & \\
$\quad \&$ marketing activities & & & \\
\hline
\end{tabular}

Table (6): Correlation between the study sample professional image and promotional/marking activities.

\begin{tabular}{lccc}
\hline Variables & $\mathrm{M} \pm \mathrm{SD}$ & $r$ & $p$ \\
\hline Professional image & $149.09 \pm 18.63$ & 0.301 & $0.000^{*}$ \\
$\begin{array}{c}\text { Nurses promotional \& } \\
\text { marketing activities }\end{array}$ & $30.95 \pm 13.98$ & & \\
\hline
\end{tabular}

Table (7): Correlation between the study sample professional image and promotional/ marking activities.

\begin{tabular}{lccc}
\hline Variables & $\mathrm{M} \pm \mathrm{SD}$ & $r$ & $p$ \\
\hline $\begin{array}{l}\text { Nurses job satisfaction } \\
\text { \& professional image }\end{array}$ & $163.59 \pm 20.38$ & & \\
Nurses promotional & $30.95 \pm 13.98$ & 0.218 & $0.000^{*}$ \\
\& marketing activities & & & \\
\hline
\end{tabular}

\section{Discussion}

The findings of the current study showed that the numbers of female nurses are more than male nurses; this may be due to the dominance of females in the nursing profession and recency of male involvement in nursing. More than one third of the study sample' age ranged from 30 to 40 years. About half of the sample participants were diploma nurses, this may be due to the number of educational institutions and schools graduating diploma nurses are more than the number of faculties graduating bachelor degree nurses. Also more than half of the study sample had experience of more than 15 years, this may be due to more than half of the sample ages ranged from 30 to 40 years and nurses were employed in governmental hospitals after having diploma degree. More than $84 \%$ of the sample was staff nurses this may be due to the fact that the majority of nurses in hospital were bed side nurses and less number of nurses hold supervisory positions.

Job satisfaction were classified into six major dimensions as follow: Salary and fringe benefits, group cohesion, work pressure, independence and flexibility, relationship with doctors and supervisors and Professional Pride.

Work pressure was found to be an important factor of low job satisfaction as high percentage of the study sample agreed that they are suffering from work pressure. More than two thirds of them agreed that work pressure exists. This may be due to shortage of bed side nurses and insufficient nurse patient ratio, close or too much supervision that usually accompanied by bureaucracy on nurses work increase their tension also too much paper work or documentation of none nursing and secretary papers added to the patient care activities make the staff nurse in severe pressure as they need to provide both care and documentation for each individual patient.

These results are consistent with, Rountree \& Porter [13] who reported that when bed side nurses experience overload and become dissatisfied they decide to leave employment in hospitals. In the same context Ge, et al. [14] reported that work overload are the factor that make nurses in their middle age frustrated and dissatisfied with their jobs, also Atefi, Abdullah, Wong \& Mazlom [15] who revealed that high workloads and shortage of nurses were major factors that caused job dissatisfaction among nurses.

Group cohesion was one of the most important factors of high job satisfaction as high percentage of the study sample agreed for that. About two thirds of the sample agreed on its items. This may be due to the importance of team work and team spirit in nursing job. Nurses works for long hours every day and have the same goal which make them all together grouped to maintain patient's life, recover from illness, providing care and discharging healthier individual. Also there were little conflicts between colleges which indicate good work relationship and effective work groups.

The results of the current study were matched with a study to determine the impact of a teambuilding intervention on group cohesion, nurse satisfaction, and turnover rates conducted by DiMeglio, et al., [16] who found that Targeted, unit-based strategies can be an effective means of reducing turnover rates and improving group cohesion which intern improve nurse satisfaction. In the same context, Li., et al. [17] reported that Nurse managers and hospital administrators should be aware of the benefits of group cohesion and organizational commitment in promoting nurses job satisfaction and preventing dissatisfaction and burnout.

Relationship with doctors and supervisors was the second important dimension of job satisfaction as high percentages of the study sample agreed for that. More than half of them saw that the relation- 
ship with doctors and supervisors were important in predicting job satisfaction. From the investigator point of view, this may be due to good work relationship between staff nurses and supervisors as supervisory positions are held by their colleagues who are working together for a long time. One item that may affect relationship with supervisors negatively was inadequate financial recognition for work achievement and this may be explained in the light of limited resources for funding financial promotion for staff as the setting is governmental one.

The result of the study were matched with Tourangeau, Patterson, Saari, Thomson \& Cranley [18] who found that nurses experiencing more positive relationships with supervisors, exhibiting more job satisfaction. In the same context Atefi, et al. [15] concluded that Nurse managers should ensure a flexible practice environment with opportunities for nurses to participate in hospital's policies and governance. Policy makers should consider nurses' professional development needs, and implement initiatives to improve nurses' rewards and other benefits as they influence job satisfaction. Also Ellenbecker, Boylan \& Samia [19] found that Nurses reported on the "respect of colleagues and physicians", "collegiality with physicians", and "physician-nurse relationship" and considered it a source of satisfaction

Professional pride is among the important factors predicting job satisfaction as about more than half of the study sample identified having professional pride. This may be due to internal emotion held by those who aligned to this profession to oppose and face the society that held negative and unsupportive opinions toward their profession. One another rational for professional pride is providing care for ill and suffering humans which give them a spiritual sensation of pride and appreciation of their exceptional work.

The results of the current study were matched with Stratton [20] who reported that nurses are knowledgeable, and never stop learning about their craft. nurses should take pride in their remarkable abilities and gratification from providing safe, competent, and compassionate care to patients, as nursing is an exceptional profession. In the same context Carlson, et al. [21] reported that nurses perceived their professional work as holistic and respectful profession that make them proud to work in also Milisen De Busser, Kayaert, Abraham \& de Casterlé [22] found that Most nurses were proud to be a nurse and considered themselves competent health professionals having great responsibility.
Independence and flexibility was important factor of job satisfaction as more than half of the study sample agreed that it is important for maintaining job satisfaction. From the investigator point of view, this may be due to severe shortage of nurses that result in limited flexibility in scheduling work time. Beside the inflexible governing policies applied in the hospital.

The results of the current study are matched with the results of Atefi, et al. [15] who found that nurses participating in the study were demonstrated limited autonomy and lack of flexibility in work and scheduling their time. In the other hand, Tourangeau, Patterson, Saari, Thomson \& Cranley [18] reported that Study participants identified having autonomy as an incentive to remain working in home care.

Salary and fringe benefits was the most effective predictor of job satisfaction. About half of them agreed that their Salary and fringe benefits were satisfactory. This may be due to low salaries offered in such governmental hospitals compared to private ones at the national level and compared to nurses salaries in other countries. Beside the importance of the salary for maintaining professional and personal life in an economically unstable Egyptian society. Also another factor that leads to dissatisfaction was unreasonable health insurance and pension.

The results of the current study are congruent with Atefi, Abdullah, Wong \& Mazlom [15] who found that nurses were dissatisfied with their reward, promotion and fringe benefits. They were also dissatisfied with the unfair and unjust distribution of salary in the healthcare organizations. On the other hand Tourangeau, et al. [18] reported that nurses were satisfied with salary and benefits.

Professional image is classified into eight dimensions: Technical skills, Intellectual-cognitive Skills, Organizational skills, Social and communication skills, Professional attitude, Perceived importance of nursing care aspects to professional nursing, perceptions of society's image of nursing and Nurses' own image.

Regarding technical skills about three quarters of study participants perceived themselves as being technically competent that foster professional image. This may be due to their prolonged experience in the field of nursing.

Regarding intellectual-cognitive skill about three quarters of the study participants considered themselves as being intellectually competent. This 
may be related to the result that about half of the study sample holding academic degrees ranging from technical institute up to master degree so, their intellectual abilities such as ability to transfer knowledge and using nursing process is basically well seated.

Regarding organizational skills about three quarters of the study sample considered themselves as being competent in it. This may be as a result of having long years of experience that makes them competent in both direct care and administrative activities.

Regarding social and communication skills about more than three quarters of the study sample considered themselves as being competent in it. This may be due to the nature of nursing profession which needs to communicate effectively at every facet of nursing care delivery. Communication at the level of staff nurses with each other's and with supervisors in terms of reporting, with the doctors for providing and seeking medical information, with relatives of the patient in terms of providing support and decrease confusion about the patient health status.

Regarding professional attitude about more than three quarters of the study participants considered themselves as possessing professional attitude which create professional positive image. This may be related to the fact that about half of the sample holding academic degrees starting from technical institute up to master degree and the presence of in service training and an evaluating team that regularly provide evaluation and feedback in a regular base.

The majority of the study nurses have a positive professional self-image. Nurses rated themselves more competent in "care" (social-organizationalpsychological) skills than in "cure" (medicaltechnical) skills. and this results confirmed the results of De Vliegher et al., [23] and Ellenbecker et al., [19] who found a relatively similar results for care and cure dimensions.

Regarding perceived importance of nursing care aspects to professional nursing the majority of the study sample considered it important to nursing profession. The result of the current study is consistent with De Vliegher et al., [23] who reported that only $(20.1 \%)$ of study sample do not recognize the importance of nursing interventions.

Regarding perceptions of society's image of nursing about two thirds of the study sample agree on its items. In regard to Nurses own image about two thirds of the sample agree on its items. When comparing the nurses own image and society's perception and image of nurses with each other's the finding was quite similar except for the item stating that nursing doesn't require much education there was extremely varied responses as regarding society and nurse own image. The result of the present study are contradicted with Hoeve, Jansen, \& Roodbol [8] who found that nurses own image and self perception is very high relative to society's perception and image.

Regarding to nursing promotional and marketing activities about one third of the study participants have a promotional and marketing activities that indicate low level of marketing nursing profession. This may be due to work overload, shortage of time of nurses as the majority of the sample are females and having family responsibilities who have no extra time after work hours to do promotional activities, about half of the sample are diploma nurses who are not at the level of lecturing, making presentations at national or international conference. In addition majority of the sample were staff nurses who have limited access to external sponsoring bodies and who have limited effect in changing hospital policy toward funding internal and external marketing activities.

The result of the current study is matched with Kagan et al., [24] who reported that the paucity of marketing activity by nurses might be the lack of policy and programs for promoting the image and status of the profession on a national or organizational level. Beside the contribution of nurses' position and rank to marketing of the nursing profession, as the more senior the nurse's position and rank the more marketing they engaged in. Nurses at senior executive levels are responsible, among other things, for public relations, marketing, information and technology. Also Emeghebo [25] reported that None of the RNs in his study was willing to promote nursing, and in fact, all participants reported that nurses generally discourage potential nurses from pursuing nursing as a career.

The current study findings indicate that there was no relationship between study sample job satisfaction and promotional \& marketing activities. The result is statistically significant but in fact both satisfaction with the profession and marketing it were low. The result of the current study was contradicted with Kagan, et al., [24] who found a direct association between study sample job satisfaction and marketing activities. 
The current study findings indicate that there was a positive relationship between study sample professional image and promotional \& marketing activities. The result of the current study is logically accepted as those with higher professional images who were mainly holding supervisory and administrative position do more for marketing as their higher awareness of and commitment to public relations and nursing-wide issues could explain why they performed much more promotion or marketing of the profession than staff nurses in specialized units. The result of current study were inconsistent with the result of ting [11] who found no direct association between nurses' professional image and their efforts to market the profession.

The current study findings indicate that there was a weak positive relationship between study sample total job satisfaction \& professional image and promotional \& marketing activities as highly satisfied nurses with high professional image perception having high level of promotional and marking activities.

\section{Conclusion:}

The present study concluded that there was a relationship between study sample job satisfaction $\&$ professional image and promotional \& marketing activities. As highly satisfied nurses with high professional image perception having high level of promotional and marking activities.

Regarding job satisfaction the study sample has low job satisfaction with mean percentage of about $59 \%$. Regarding the professional image the study sample have moderate professional image with mean percentage of $68 \%$. Regarding the promotional \& marketing activities the study sample have very low promotional activities with mean percentage of about $36 \%$.

\section{Recommendations:}

In the light of the findings of the present study, the following are recommended:

- Measure nurses job satisfaction in a regular base in order to find out areas of satisfaction to promote and areas of dissatisfaction to solve and improve.

- Encourage nurses to be more visible and present themselves as a respected professionals.

- Improve nurses image and status through involving nurses in public talks and mass media presentation to raise the public awareness of the profession.
- Developing strategies to improve nurses image throughout the nursing curriculum.

\section{- Develop a marketing plan:}

Internal (with in the hospital) through providing training courses and salary bonuses for good performing nurses.

\section{External (outside the hospital) through:}

- Inviting stallholders and nurses during discussion of public and health related issues to present latest nursing solution for current and forecasted health problems as a part of the health care team members.

- Present positive and initiative nurses models in mass media.

- Funding a part of nursing syndicate activities to ward promoting and marketing nurses profession through presenting strengths inherent to the nursing profession.

\section{References}

1- WU L., LOW M., TAN K., LOPEZ V. and LIAW S.: Why not nursing? A systematic review of factors influencing career choice among healthcare students. International Nursing Review, 62 (4): 547-562, 2015.

2- FARAGE M.: "Economic Analysis of The Nurse Shortage in Egypt" available at http://www.ciaonet.org/catalog/ 2785 (accessed 16 October 2015), 2008.

3- MOSADEGHRAD A.: Factors influencing healthcare service quality. International Journal of Health Policy and Management, 3 (2): 77-89, 2014.

4- LORBER M., and SKELA SAVIC B.: Job satisfaction of nurses and identifying factors of job satisfaction in Slovenian Hospitals. Croatian Medical Journal, 53 (3): 263 70, 2012.

5- American Nurses Credentialing Center (ANCC) 2014 Magnet ${ }^{\circledR}$ Application Manual. Available at: http: //www .nursecredentialing.org/Magnet ApplicationManual (accessed 6 October 2015), 2013.

6- SEAGO J.A., et al.: The nursing shortage: is it really about image? Journal of Healthcare Management, 51 (2): 96-108, 2006.

7- SAYMAN D.M.: Fighting the trauma demons: What men in nursing want you to know. Nursing Forum, 50 (1): 919. doi: 10.1111/nuf .12073, 2014.

8- HOEVE Y.T., JANSEN G. and ROODBOL P.: The nursing profession: public image, selfconcept and professional identity. A discussion paper. Journal of Advanced Nursing, 70 (2): 295-309, 2014.

9- MORRIS-THOMPSON T., SHEPHERD J., PLATA R. and MARKS-MARAN D.: Diversity, fulfillment and privilege: The image of nursing. Journal of Nursing Management, 19 (5): 683-692, 2011.

10- NEILSON G.R. and JONES M.C.: What predicts the selection of nursing as a career choice in 5 th and 6 th year 
school students. Nurse Education Today, 32 (5): 588-593, 2012.

11-TING S.: The effect of internal marketing on organizational commitment: Job involvement and job satisfaction as mediators. Educational Administration Quarterly, 47 (2): 353-382, 2011.

12-SOMERS M.J., FINCH L. and BIRNBAUM D.: Marketing nursing as a pro- fession: integrated marketing strategies to address the nursing shortage. Health Marketing Quarterly, 27 (3): 291-306, 2010.

13- ROUNTREE B.H. and PORTER R.: The experience of work in hospital settings and nurse's perceived need or desire to look for a less stressful, more satisfying job. International Journal of Organization Theory and Behavior, 12 (1): 1, 2009.

14-GE C., FU J., CHANG Y. and WANG L.: Factors associated with job satisfaction among Chinese community health workers: A cross-sectional study. BMC Public Health, 11 (1): 884, 2011.

15-ATEFI N., ABDULLAH K.L., WONG L.P. and MAZLOM, R.: Factors influencing registered nurses perception of their overall job satisfaction: A qualitative study. International Nursing Review, 61 (3): 352-360, 2014.

16- DIMEGLIO K., PADULA C., PIATEK C., KORBER S., BARRETT A., DUCHARME M. and CORRY K.: Group Cohesion and Nurse Satisfaction: Examination of a TeamBuilding Approach. Journal of Nursing Administration, 35 (3): 110-120, 2005.

17- LI A., EARLY S.F., MAHRER, N.E., KLARISTENFELD J.L. and GOLD J.I.: Group cohesion and organizational commitment: Protective factors for nurse residents' job satisfaction, compassion fatigue, compassion satisfaction, and burnout. Journal of Professional Nursing, 30 (1): 8999, 2014.

18- TOURANGEAU A.E., PATTERSON E., SAARI M., THOMSON H. and CRANLEY L.: Work-related factors influencing home care nurse intent to remain employed. Health Care Management Review, 42 (1): 87-97, 2017.

19- ELLENBECKER C.H., BOYLAN L.N. and SAMIA L. What home healthcare nurses are saying about their jobs. Home Healthcare Now, 24 (5): 315-324, 2006.

20- STRATTON M.: The Power of Professional Pride. Aorn Journal, 104 (5): 381-382.

21- CARLSON E., RÄMGÅRD M., BOLMSJÖ I. and BENGTSSON M.: Registered nurses' perceptions of their professional work in nursing homes and home-based care: A focus group study. International, 2014.

22- MILISEN K., DE BUSSER T., KAYAERT A., ABRAHAM I. and de CASTERLÉ B.D.: The evolving professional nursing self-image of students in baccalaureate programs: A cross-sectional survey. International Journal of Nursing Studies, 47 (6): 688-698, 2010.

23- DE VLIEGHER K., MILISEN K., WOUTERS R., SCHEEPMANS K., PAQUAY L., DEBAILLIE R. and DE CASTERLÉ B.D.: The professional self-image of registered home nurses in Flanders (Belgium): A crosssectional questionnaire survey. Applied Nursing Research, 24 (1): 29-36, 2011.

24- KAGAN I., RN E.B., RN L.T. and RN N.S.: Promotion or marketing of the nursing profession by nurses, International Nursing Review, 62: 368-376, 2015.

25- EMEGHEBO L.: The image of nursing as perceived by nurses. Nurse Education Today, 32 (6): e49-e5, 2012.

\section{العلاقة بين الرضا الوظيفى والصورة المهنية وتسويق الممرضات لمهنة التمريض}

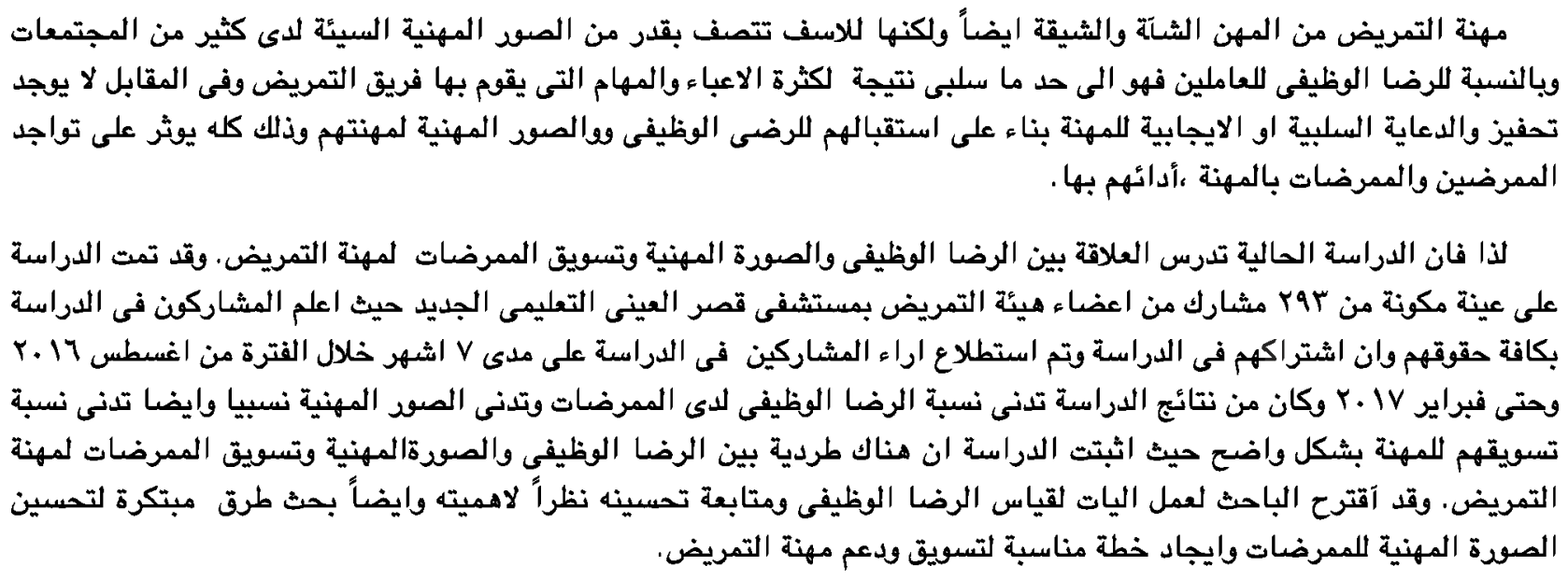

